\title{
Prevalence and Genetic Characterization of Rotavirus Infections Among Children Under Five Years in Mutaho Health District, Gitega Province and Bujumbura Municipality, Burundi
}

\author{
Cassien Nduwimana $^{1^{*}} \quad$ Eddy Okoth Odari $^{1} \quad$ James Nyangao $^{2} \quad$ Carlene Sang $^{2} \quad$ Raphael W. Lihana ${ }^{2}$ \\ 1. Jomo Kenyatta University of Agriculture and Technology, School of Biomedical Sciences, Nairobi, Kenya \\ 2. Kenya Medical Research Institute, Nairobi, Kenya
}

\begin{abstract}
Rotavirus is the leading cause of severe diarrhea in children under five years worldwide. It is ranked as a priority for vaccine. In Burundi, vaccine against rotavirus was implemented in 2013. The impact of recent rotavirus vaccination on morbidities in Burundi is not well established. Moreover, no study has been carried out to document the genetic diversity of rotavirus strains circulating in Burundi. This cross-sectional health facilitybased study aimed at determining the prevalence and molecular characteristics of rotavirus infections among children under five years of age in Mutaho Health District and the Municipality of Bujumbura, in Burundi. Stool specimens were collected from children presenting with acute diarrhea. These specimens were tested for rotavirus antigen using Diagnostar ${ }^{\circledR}$ rapid test kit. Positive stool samples were confirmed at the Kenya Medical Research Institute (KEMRI) by ELISA. Positive confirmed samples underwent RT-PCR, G and P genotyping by multiplex semi-nested PCR using a cocktail of type specific primers or by sequencing. A total of 646 participants were enrolled in this study. The overall prevalence of rotavirus was $6.2 \%$ (40/646) with $4.0 \%$ (16/400) in Mutaho health district and $9.7 \%(24 / 246)$ in the Municipality of Bujumbura. Rotavirus detection rate tended to increase as the level of precipitation went down, showing a significant negative association between the two variables. $(\mathrm{OR}=15.2 ; \mathrm{P}=0.0001)$. In addition, rotavirus detection rate was higher in Bujumbura Municipality than in Mutaho health district $(\mathrm{OR}=2.6 ; \mathrm{P}=0.005)$. Two $\mathrm{G}$ genotypes were identified, $\mathrm{G} 1$ the predominating $\mathrm{G}$ genotype accounted for 53.8\% (14/26) followed by G12 (46.2\%, 12/26). The prevalence of the genotype G1 of Group A rotavirus was significantly higher in Bujumbura Municipality than in Mutaho health district while G12 predominated in Mutaho health district $(\mathrm{OR}=7.33 ; \mathrm{P}=0.026)$. Rotavirus strains from pigs might have contributed to the high prevalence of human G12 rotavirus in that area. Three different $\mathrm{P}$ types were identified $\mathrm{P}[8]$ the most common, followed by $\mathrm{P}[6]$ and $\mathrm{P}[4]$. The most common G/P combination genotype was G1P[8] which accounted for $45.5 \%$ of all rotavirus genotypes identified, followed by G12 P [8] (41.0\%), G1P [6] (4.5\%), G12 P [6] (4.5\%) and G12 P [4] (4.5\%). The emergence of G12 rotavirus strains which share neither G nor P genotypes with currently used rotavirus vaccines raises public health concerns as they have the potential to challenge their efficacy. Therefore, we recommend to initiate and maintain a continuous rotavirus strain surveillance in Burundi so as to monitor trends in the occurrence of these prevailing and potentially emerging new strains.
\end{abstract}

Keywords: Rotavirus, diarrhea, genetic diversity, prevalence, Mutaho, Bujumbura, children

DOI: $10.7176 / \mathrm{JBAH} / 9-10-04$

Publication date:May $31^{\text {st }} 2019$

\section{Introduction}

Diarrheal illness remains a major threat to child health in developed and developing countries (WHO, 2013). It is one of the principal causes of morbidity and mortality among children in developing countries where numerous cases occur without identification of the specific etiologic agents (Kapoor et al., 2009).

Globally, rotavirus causes more than 450,000 deaths each year in children under five and is responsible for millions of hospitalizations and clinic visits (PATH, 2013).

Rotavirus is recognized as the leading cause of severe diarrheal disease hospitalizations in young children and infants in Africa (Abugalia et al., 2011;WHO, 2013). In Burundi, before the introduction of rotavirus vaccine, it was estimated that, each year, one third of all under-five diarrheal disease hospitalizations and more than 3500 deaths among children under five years were caused by rotavirus (PATH, 2013). The Global Alliance for Immunizations ranked rotavirus as a priority for vaccine. In Burundi, vaccine against rotavirus was implemented in December 2013 (GAVI, 2013).

Rotavirus belongs to the Reoviridae family. They are non-enveloped viruses, with a triple-layered capsid protein of icosahedral symmetry with a genome consisting of 11 segments of ds RNA (Greenberg \& Estes, 2009; Fischer \& Gentsch, 2004). They are characterized by substantial genetic diversity, as evidenced by the presence of multiple serotypes (Bernstein, 2009). The VP 7 and VP4 encoding gene segments are the basis of a binary classification system (Ianiro, et al., 2015; Desselberger et al., 2009). So, viruses are referred to as G-types and P-Types (Greenberg \& Estes, 2009). In Burundi, no study has been conducted to establish the prevalence of 
rotavirus infections among children, over five years after the vaccine was integrated in the children routine immunization scheme.

\section{Methodology}

\subsection{Study design and sampling design}

This was a health facility based cross-sectional study. The study subjects were consecutively enrolled.

\subsection{Study setting and population}

The study was conducted in six health facilities of Mutaho Health District and seven health facilities of Bujumbura Municipality. In Mutaho health district, the study sites included Mutaho District Hospital and Mutoyi Hospital, Bugendana, Mutaho, Rwisabi and Mutoyi health Centers. In Bujumbura Municipality, the study was conducted at the Prince Regent Charles Hospital (HPRC), Buyenzi health center (CMC Buyenzi), Bwiza-Jabe, Kamenge, Mirango and Kinama and health centers.

The study population comprised children under five years presenting with acute diarrhea between November 2017 and March 2018 and then in July 2018 in Mutaho health district and April to July 2018 in Bujumbura Municipality. Only children whose parents or guardians gave written informed consent were enrolled in the study.

\subsection{Data collection instruments}

A structured questionnaire was used to collect socio-demographic and clinical data (age, sex, vaccination status, duration and frequency of diarrhea, department of health care) from parents/guardians of children enrolled in this study. Further, a fecal sample was taken from each participant. Samples were stored at $-20^{\circ} \mathrm{C}$ within the local facilities before they were transported to the National Institute of Public Health (INSP) in Burundi where they were stored at $-80^{\circ} \mathrm{C}$ until the shipment to the Kenya Medical Research Institute (KEMRI), Center for Virus Research in Nairobi, Kenya for further analyses.

\subsection{Rotavirus antigen detection by ELISA}

One milliliter of $10 \%$ fecal suspensions was prepared by adding a pea-sized portion (approximately $0.1 \mathrm{~g}$ or $100 \mu \mathrm{L}$ for liquid specimens) of stool sample into $2 \mathrm{~mL}$ cryotubes containing $1 \mathrm{~mL}$ of Prospect ${ }^{\mathrm{TM}}$ Rotavirus sample diluent, vortexed and clarified by centrifugation at $2000 \mathrm{rpm}$ for 5 minutes. Thereafter, the clarified supernatant was used for Group A rotavirus antigen detection using a solid phase sandwich type ELISA method according to the manufacturer instructions (Prospect ${ }^{\mathrm{TM}}$ Rotavirus Microplate Assay, Oxoid Ltd, United Kingdom) (AFRSN, 2017). The optical density (OD) values above the cut-off value of 0.265 (OD of negative control + $0.20)$ were considered as positive for rotavirus antigen.

\subsection{Molecular analysis of ELISA-positive samples}

2.5.1 Extraction of rotaviral ds RNA

The ds RNA of rotavirus was extracted according to the manufacturer's instructions using the QIamp viral RNA mini kit (Qiagen/Westburg, Leusden, Netherlands). In this regard, 10\% stool suspensions were prepared in distilled water, mixed by vortexing and clarified by centrifugation. Thereafter, $140 \mu \mathrm{L}$ of the supernatant was used for ds RNA extraction which yielded $60 \mu \mathrm{L}$ of RNA extract (AFRSN, 2017).

2.5.2 Amplification (RT-PCR) and genotyping

Amplification (RT-PCR) and genotyping were carried out as previously described (WHO, 2009; AFRSN, 2017). Briefly, RT-PCR of rotavirus ds RNA involved three steps; i.e. ds RNA denaturation, Reverse transcription of ds RNA and PCR amplification of cDNA. Separately for VP7 and VP4 encoding gene segments, $1 \mu \mathrm{L}$ of each random primer were added into a PCR tube containing $8 \mu \mathrm{L}$ of extracted RNA. After a brief centrifugation, the ds RNA was incubated for 5 minutes at $+94^{0} \mathrm{C}$ for denaturation and then immediately chilled in an ice bath for 5 minutes. The primers used were Beg9 and End9 for VP7 gene and Con2 and Con3 for the VP4 gene (WHO, 2009; AFRSN, 2017).

The reactions included a total volume of $3.2 \mu \mathrm{L}$ of RT master-mix per reaction $(1 \mu \mathrm{L}$ dNTPs, $0.2 \mu \mathrm{L}$ AMV RTase and $2.0 \mu \mathrm{L}$ of AMV buffer). This was added into each PCR tube containing the extracted ds RNA, followed by incubation at $42^{\circ} \mathrm{C}$ for 30 minutes for reverse-transcription. Subsequently, the newly synthesized cDNA was subjected to PCR amplification. For first round PCR, the total volume of master-mix prepared per reaction was $40 \mu \mathrm{L}$ in these proportions: $4 \mu \mathrm{L}$ of dNTPs, $4 \mu \mathrm{L}$ of Taq Buffer, $2.4 \mu \mathrm{L}$ of $\mathrm{MgCl}_{2}(50 \mathrm{mM}), 30 \mu \mathrm{L}$ of ddH2O and $0.3 \mu \mathrm{L}$ of Taq Polymerase (WHO, 2009; AFRSN, 2017).

2.5.3 Genotyping of Rotavirus using VP7 and VP4 specific primers.

Rotavirus genotyping involved a cocktail of G1-G4, G8, G9, G10 and G12 genotype specific primers (Gouvea et al., 1990) (Table 1) and the consensus primer Beg9 for VP7 and the consensus primer Con3 alongside a cocktail of [P4], [P6], [P8], [P9] and [P10] type specific primers (Fischer \& Gentsch, 2004) (Table 2). 
For second round PCR (multiplex semi-nested PCR), working on ice, $40 \mu \mathrm{L}$ of master-mix comprising 10x Taq buffer $4 \mu \mathrm{L}, 25 \mathrm{mM} \mathrm{MgCl} 2.4 \mu \mathrm{L}$, Taq Polymerase $(5 \mathrm{U} / \mu \mathrm{L}) 0.3 \mu \mathrm{L}$, dNTPs $(10 \mathrm{mM}) 4 \mu \mathrm{L}$ was added into a PCR tube containing $1 \mu \mathrm{L}$ of first PCR product, $1 \mu \mathrm{L}$ of reverse primer (End 9 for VP7 and Con 3 for VP4) and $1 \mu \mathrm{L}$ of each type specific primer. The PCR was run after a brief centrifugation. The second PCR products $(7 \mu \mathrm{L}$ per sample) were then run onto a $1 \%$ TAE-agarose gel at $94 \mathrm{~V}$ for 30 minutes followed by determination of the genotypes based on their specific size observed under UV light. Positive and negative controls as well as a 100 bp ladder (molecular weight marker) were used for quality control purpose and for precision in the measure of bands size. Samples failing to genotype by RT-PCR underwent sequencing using first PCR products and primer sets.

2.5.4 Sequencing of VP7 and VP4 genes of detected Rotavirus strains

Sequencing reactions were performed using the ABI Big Dye TerminatorV3.1 Cycle sequencing Kit following the manufacturer's instructions. The same primers for PCR were used for sequencing as previously described (Gouvea et al., 1990).

Table 1. Oligonucleotide primers used for G (VP7) typing

\begin{tabular}{|l|l|l|l|}
\hline Genotype & Sequence (5'-3') & Position & Primer \\
\hline G1 & CAAGTACTCAAATCAATGATGG & $314-335$ & aBt1 \\
\hline G2 & CAATGATATTAACACATTTTCTGTG & $411-435$ & aCT2 \\
\hline G3 & CGTTTGAAGAAGTTGCAACAG & $689-709$ & aET3 \\
\hline G4 & CGTTTCTGGTGAGGAGTTG & $480-498$ & aDT4 \\
\hline G8 & GTCACACCATTTGTAAATTGG & $178-198$ & aAT8 \\
\hline G9 & CTAGATGTAACTACAACTAC & $756-776$ & aFT9 \\
\hline G12 & CCGATGGACGTAACGTTGTA & $548-567$ & bG12 \\
\hline
\end{tabular}

Table 2. Oligonucleotide primers for $P$ (VP4) typing

\begin{tabular}{|l|l|l|l|}
\hline Genotype & Sequence (5'-3') & Position & Primer \\
\hline $\mathrm{P}[4]$ & CTATTGTTAGAGGTTAGAGTC & $474-494$ & $2 \mathrm{~T}-1$ \\
\hline $\mathrm{P}[6]$ & TGTTGATTAGTTGGATTCAA & $259-278$ & $3 \mathrm{~T}-1$ \\
\hline $\mathrm{P}[8]$ & ACTTGGATAACGTGC & $339-356$ & $1 \mathrm{~T}-1$ \\
\hline $\mathrm{P}[9]$ & TGAGACATGCAATTGGAC & $385-402$ & $4 \mathrm{~T}-1$ \\
\hline $\mathrm{P}[10]$ & ATCATAGTTAGTAGTCGG & $575-594$ & $5 \mathrm{~T}-1$ \\
\hline
\end{tabular}

2.5.5 Phylogenetic analysis of partial VP7 and VP4 genes nucleotide sequences.

The evolutionary distances between rotavirus strains from Burundi and reference strains from GenBank were established using the Maximum Likelihood method (Tamura \& Nei, 1993). Evolutionary analyses were conducted in MEGA6 (Tamura et al., 2013).

\subsection{Data management and analysis}

Data were analyzed using the Statistical Package for Social Sciences (SPSS for IBM software version 21). The Chi-square test was used to test the statistical significance of differences observed between different proportions. The association between rotavirus positivity, $G$ and $P$ genotypes prevalence and socio-demographic characteristics was estimated as odds ratio (OR) between rotavirus infected and rotavirus non infected subjects. A P value $<0.05$ was considered an indicator of statistical significance. Descriptive summaries were presented in tables and figures.

\subsection{Ethical clearance}

Authorization to conduct this study was obtained from the Burundian Ministry of Public Health and the Fight against AIDS. Ethical clearance was obtained from the National Ethics Review Committee in Burundi (BERC 14/10/2017).

\section{Results}

\subsection{The prevalence of rotavirus infections}

A total of 646 participants were enrolled in this study. More than a half $(55 \%,(355 / 646))$ of children who participated in this study were male. The mean age for these children was 21.58 months (SD: 14.29 ). Over $60 \%$ of them were under 2 years of age. According to their parents/guardians or care takers, $584(90.4 \%)$ were vaccinated, $36(5.6 \%)$ were not vaccinated and the vaccination status of $26(4.0 \%)$ of them was not known (Table 3).

The overall prevalence of rotavirus infections was $6.2 \%(40 / 646)$. The prevalence of rotavirus was significantly higher in dry than rainy season with a peak during the month of July $2018(15.8 \%)$ which accounted for $82.5 \%$ of all cases recorded during the study $(\mathrm{OR}=15.2, \mathrm{P}=0.0001)$. The month of July is the driest month 
in Burundi with an average precipitation of $3 \mathrm{~mm}$ (Figure 1).

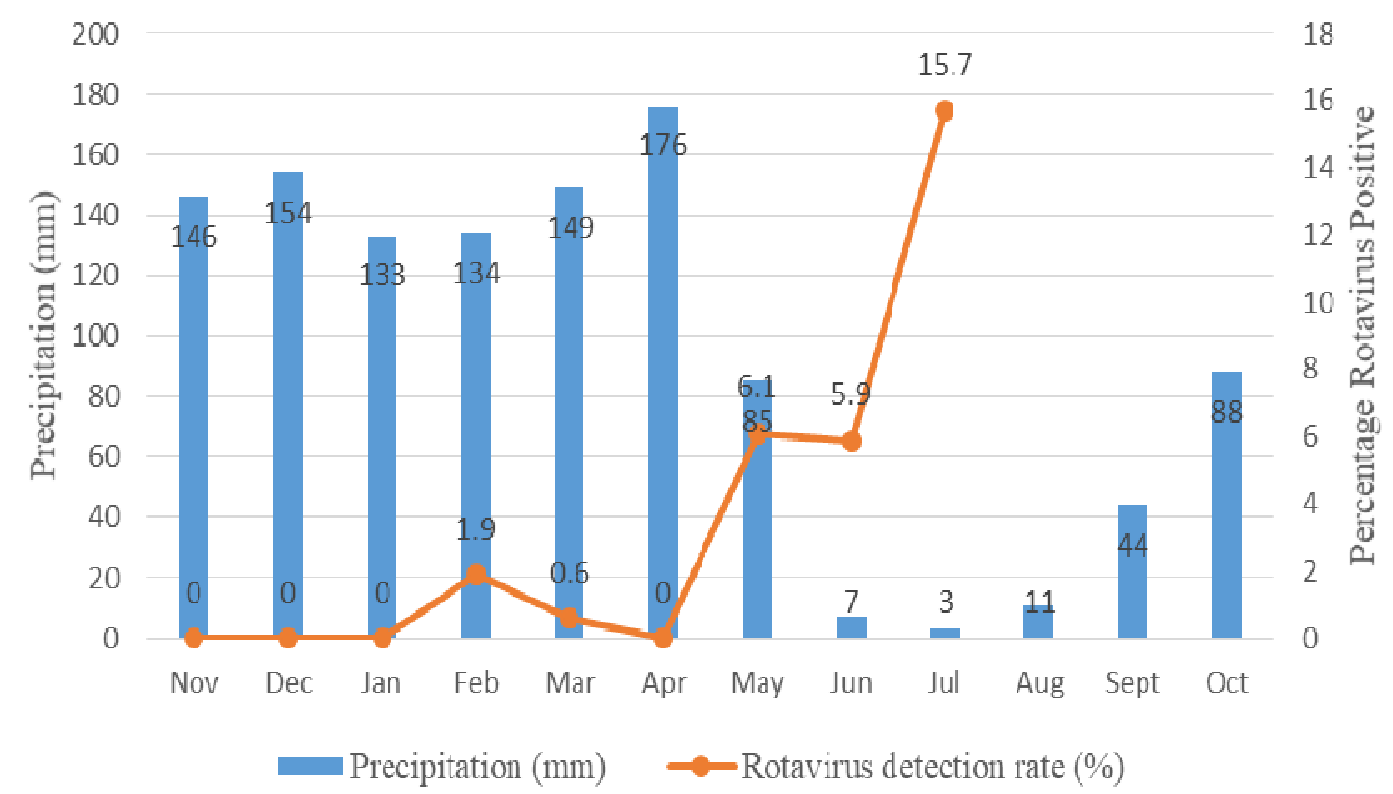

Figure 1. Trend of rotavirus detection rate over different months of the year and its association with the level of precipitation in Mutaho health district and the Municipality of Bujumbura. This figure depicts the association between the level of precipitation and monthly rate of detection of rotavirus among children under 5 years with acute diarrhea. It shows a peak of rotavirus detection rate in July 2018, the driest month of the year. The overall prevalence of rotavirus infections was significantly higher in Bujumbura Municipality than in Mutaho health district $(\mathrm{OR}=2.6, \mathrm{P}=0.005)$. However, there was no significant association between the prevalence of rotavirus infections and the gender of study subjects $(\mathrm{OR}=0.9, \mathrm{P}=0.874)$ or the age of participants $(\mathrm{OR}=1.73, \mathrm{P}=0.086)$. In addition, no significant difference of rotavirus detection rate was found between vaccinated and non-vaccinated children $(\mathrm{OR}=0.41, \mathrm{P}=0.322)$ (Table 3$)$.

Table 3. Association between socio-demographic characteristics, vaccination status of participants and rotavirus detection rate $(n=646)$.

\begin{tabular}{|c|c|c|c|c|c|}
\hline Variable & No. tested (\%) & Rotavirus positive by ELISA & P. value & OR & $95 \% C I$ \\
\hline \multicolumn{6}{|l|}{ Age } \\
\hline $0-23$ month & $395(61.1)$ & $29(7.3)$ & 0.086 & 1.73 & $0.81-3.91$ \\
\hline 24-59 moths & $251(38.9)$ & $11(4.4)$ & & Ref & \\
\hline \multicolumn{6}{|l|}{ Gender } \\
\hline Male & $355(55.0)$ & $21(5.9)$ & 0.874 & 0.9 & $0.47-1.71$ \\
\hline Female & $291(45.0)$ & $19(6.5)$ & & Ref & \\
\hline \multicolumn{6}{|l|}{ Residence } \\
\hline Mutaho Health District & $400(61.9)$ & $16(4.0)$ & & Ref & \\
\hline Municipality of Bujumbura & $246(38.1)$ & $24(9.7)$ & 0.005 & 2.6 & $1.35-4.99$ \\
\hline \multicolumn{6}{|l|}{ Vaccination status } \\
\hline Vaccinated & $585(90.6)$ & $39(6.7)$ & & Ref & \\
\hline Non vaccinated & $35(5.4)$ & $1(2.9)$ & 0.322 & 0.41 & $0.01-2.60$ \\
\hline Status not known & $26(4.0)$ & 0 & & & \\
\hline \multicolumn{6}{|l|}{ Seasonality } \\
\hline Rainy season & $385(59.6)$ & $4(1.0)$ & & Ref & \\
\hline Dry season & $261(40.4)$ & $36(13.8)$ & 0.0001 & 15.2 & $5.35-43.38$ \\
\hline
\end{tabular}

\subsection{Distribution of identified $G$ and $P$ types.}

3.2.1 G-types

Of the 40 stool specimens confirmed to be positive for rotavirus antigens by ELISA, 32 samples were available for RT-PCR and genotyping. For G- typing, 6 samples were PCR negative, 26 samples were successfully genotyped and two G-genotypes, G1 and G12 were identified out of 7 searched for. The genotypes G2, G3, G4, G8 and G9 were not found. The genotype G1 was found predominant (53.8\%, (14/26)), followed by G12 (46.2\%, 
(12/26)).

The prevalence of G1 genotype of Group A rotavirus was significantly higher in Bujumbura Municipality than in Mutaho health district while the G12 genotype predominated in Mutaho Health district, a rural area where farming activities are more intensive $(\mathrm{OR}=7.333, \mathrm{P}=0.026)$. The distribution of G-types was not found to be associated with the age, gender and the vaccination status of children who participated in this study, nor was it significantly associated with season (Table 4).

Table 4. Prevalence of $G$ genotypes of Group A rotavirus detected among under 5 years children with acute diarrhea in Mutaho health district and the Municipality of Bujumbura $(n=26)$.

\begin{tabular}{|c|c|c|c|c|c|}
\hline & \multicolumn{5}{|c|}{ G-genotypes distribution } \\
\hline Variable & $\begin{array}{r}\text { G1 } \\
\mathrm{n}(\%)\end{array}$ & $\begin{array}{r}\mathrm{G} 12 \\
\mathrm{n}(\%)\end{array}$ & P. value & OR & $95 \%$ CI \\
\hline \multicolumn{6}{|l|}{ Age } \\
\hline $0-23$ months & $9(56.3)$ & $7(43.7)$ & 0.618 & 1.286 & $0.479-3.452$ \\
\hline $24-59$ months & $5(50.0)$ & $5(50.0)$ & & Ref & \\
\hline \multicolumn{6}{|l|}{ Gender } \\
\hline Male & $9(69.2)$ & $4(30.8)$ & & Ref & \\
\hline Female & $5(38.5)$ & $8(61.5)$ & 0.119 & 0.278 & $0.040-1.798$ \\
\hline \multicolumn{6}{|l|}{ Residence } \\
\hline Mutaho health district & $3(27.3)$ & $8(72.7)$ & 0.026 & 7.333 & $1.272-42.294$ \\
\hline Bujumbura Municipality & $11(73.3)$ & $4(26.7)$ & & Ref & \\
\hline \multicolumn{6}{|l|}{ Vaccination status } \\
\hline Vaccinated & $13(52.0)$ & $12(48.0)$ & & & \\
\hline Non vaccinated & $1(100)$ & 0 & & & \\
\hline Status not known & 0 & 0 & 0.345 & - & \\
\hline \multicolumn{6}{|l|}{ Seasonality } \\
\hline Rainy season & $1(7.1)$ & $1(8.3)$ & & Ref & \\
\hline Dry season & $13(92.9)$ & $11(91.7)$ & 0.72 & 1.182 & $0.066-21.175$ \\
\hline
\end{tabular}

\subsubsection{P-types}

P-typing was successfully performed for 25 samples while 7 samples were PCR negative. P-typing allowed the identification of three different P-types with the most common P-type being P[8] accounting for 84.0\% (21/25) of all rotavirus P-types circulating in Mutaho Health District and in the municipality of Bujumbura, followed by $\mathrm{P}$ [6] and P [4] accounting for $8.0 \%(2 / 25)$ each. The genotypes P [9] and P [10] were not found. The distribution of $\mathrm{P}$-types was not significantly associated with season $(\mathrm{OR}=0.95, \mathrm{P}=0.072)$, the age of study subjects $(\mathrm{OR}=1.51,95 \% \mathrm{CI}: 0.94-2.41, \mathrm{P}=0.086)$, the gender of participants $(\mathrm{OR}=1.35,95 \% \mathrm{CI}=0.86-2.125$, $\mathrm{P}=0.192)$ and the vaccination status of children who participated in this study $(\mathrm{P}=0.906)($ Table 5$)$.

The predominant G/P combination genotype was G1P [8] which accounted for 45.5\% (10/25) of all rotavirus strains isolated in Mutaho health district and Bujumbura Municipality, followed by G12 P [8] (41.0\%), G1P [6] (4.5\%), G12 P [6] (4.5\%) and G12 P [4] (4.5\%). 
Table 5. Prevalence of $P$ genotypes of Group A rotavirus detected among under 5 years children with acute diarrhea in Mutaho health district and the Municipality of Bujumbura (n=25).

\begin{tabular}{|c|c|c|c|c|c|c|}
\hline & \multicolumn{6}{|c|}{ P-genotypes distribution } \\
\hline Variable & $\begin{array}{r}\mathrm{P}[4] \\
\mathrm{n}(\%)\end{array}$ & $\begin{array}{r}\mathrm{P}[8] \\
\mathrm{n}(\%)\end{array}$ & $\begin{array}{r}\mathrm{P}[6] \\
\mathrm{n}(\%)\end{array}$ & P. value & OR & $95 \% \mathrm{CI}$ \\
\hline \multicolumn{7}{|l|}{ Age } \\
\hline $0-23$ months & $1(6.3)$ & $14(87.5)$ & $1(6.3)$ & 0.086 & 1.51 & $0.94-2.41$ \\
\hline $24-59$ months & $1(11.1)$ & $6(66.7)$ & $2(22.2)$ & & Ref & \\
\hline \multicolumn{7}{|l|}{ Gender } \\
\hline Male & $1(10.0)$ & $7(70.0)$ & $2(20.0)$ & & Ref & \\
\hline Female & $1(6.7)$ & $13(86.6)$ & $1(6.7)$ & 0.192 & 1.35 & $0.86-2.125$ \\
\hline \multicolumn{7}{|l|}{ Residence } \\
\hline Mutaho health district & $1(9.1)$ & $9(81.1)$ & $1(9.1)$ & 0.966 & 1.15 & $0.75-1.76$ \\
\hline Bujumbura Municipality & $1(7.1)$ & $12(85.7)$ & $1(7.1)$ & & Ref & \\
\hline \multicolumn{7}{|l|}{ Vaccination status } \\
\hline Vaccinated & $2(8.3)$ & $20(83.3)$ & $2(8.3)$ & & & \\
\hline Non vaccinated & 0 & $1(4.8)$ & 0 & & & \\
\hline Status not known & $2(8.0)$ & $21(84.0)$ & 0 & 0.906 & - & \\
\hline \multicolumn{7}{|l|}{ Seasonality } \\
\hline Rainy season & 0 & $1(50)$ & $1(50)$ & & Ref & \\
\hline Dry season & $2(8.7)$ & $20(87.0)$ & $1(4.3)$ & 0.072 & 0.95 & $0.63-1.45$ \\
\hline
\end{tabular}

3.3 Analysis of VP7 and VP4 nucleotide sequences.

3.3.1 VP7 nucleotide sequences

Phylogenetic analysis based on VP7 nucleotide sequences revealed that within G1 rotavirus strains detected in this study, nucleotide similarities ranged between 98 and 99\%. Rotavirus G1 strains identified in this study showed 96-99\% nucleotide identity to reference G1 strains from India, Mali, Tanzania, USA and the Democratic Republic of Congo (GenBank accession numbers for reference G1 strains are JN192096, KP883165, KF976853, HM773752 and KJ870781). Circulating rotavirus G1 strains from Burundi showed nucleotide identity of only 93\% to rotavirus vaccine-strain Rotarix (GenBank accession number JN849114). Nucleotide sequences of rotavirus G12 strains identified in this study varied by 2\%. Rotavirus G12 strains from this study were closely related to reference G12 strains from South Africa, Nepal, Mozambique and USA and displayed nucleotide identity above 98\%. (GenBank accession numbers for G12 reference strains are KJ752819, LC374192, KP222840 and MF168292) (Figure 2). 


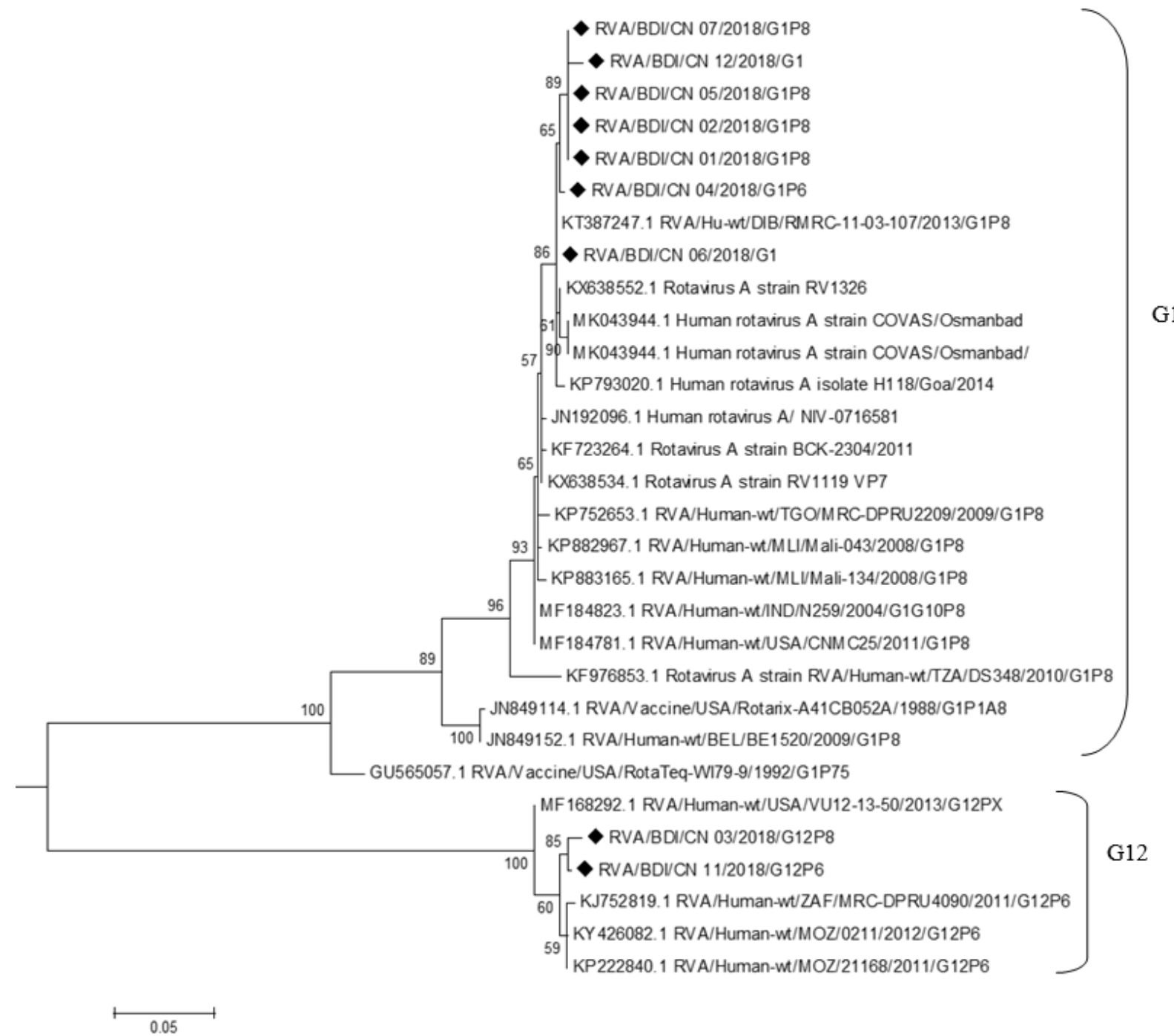

Figure 2. Phylogenetic tree of the partial VP7 gene nucleotide sequences of Group A rotavirus strains circulating in Mutaho health district and Bujumbura Municipality, Burundi. This diagram depicts the degree of similarity between VP7 nucleotide sequences of Rotavirus strains from Burundi and known Rotavirus reference strains from GenBank database. Rotavirus reference strains are indicated by accession numbers while Rotavirus strains from this study are indicated by a filled diamond symbol.

3.3.2 Analysis of VP4 nucleotide sequences

Nucleotide sequences of circulating P [8] rotavirus strains from Burundi showed 99-100\% identities to each other. Nucleotide similarity between circulating rotavirus $\mathrm{P}[8]$ strains from Burundi and reference strains from India, Belgium, the Democratic Republic of Congo, South Africa and Zimbabwe was 99\% with GenBank accession numbers MF373715, HQ392164, KP870781, KP753159, KP753226. A comparison of Burundian rotavirus P[6] strains in this study and P[6] reference strains from the Democratic Republic of Congo, Mozambique, Zimbabwe, South Africa, Russia and Brazil showed nucleotide identity ranging between 98 and 99\% with GenBank accession numbers KJ870892, KP222867, KJ753832, KJ753719, JX878655, MF695060 (Figure 3). 


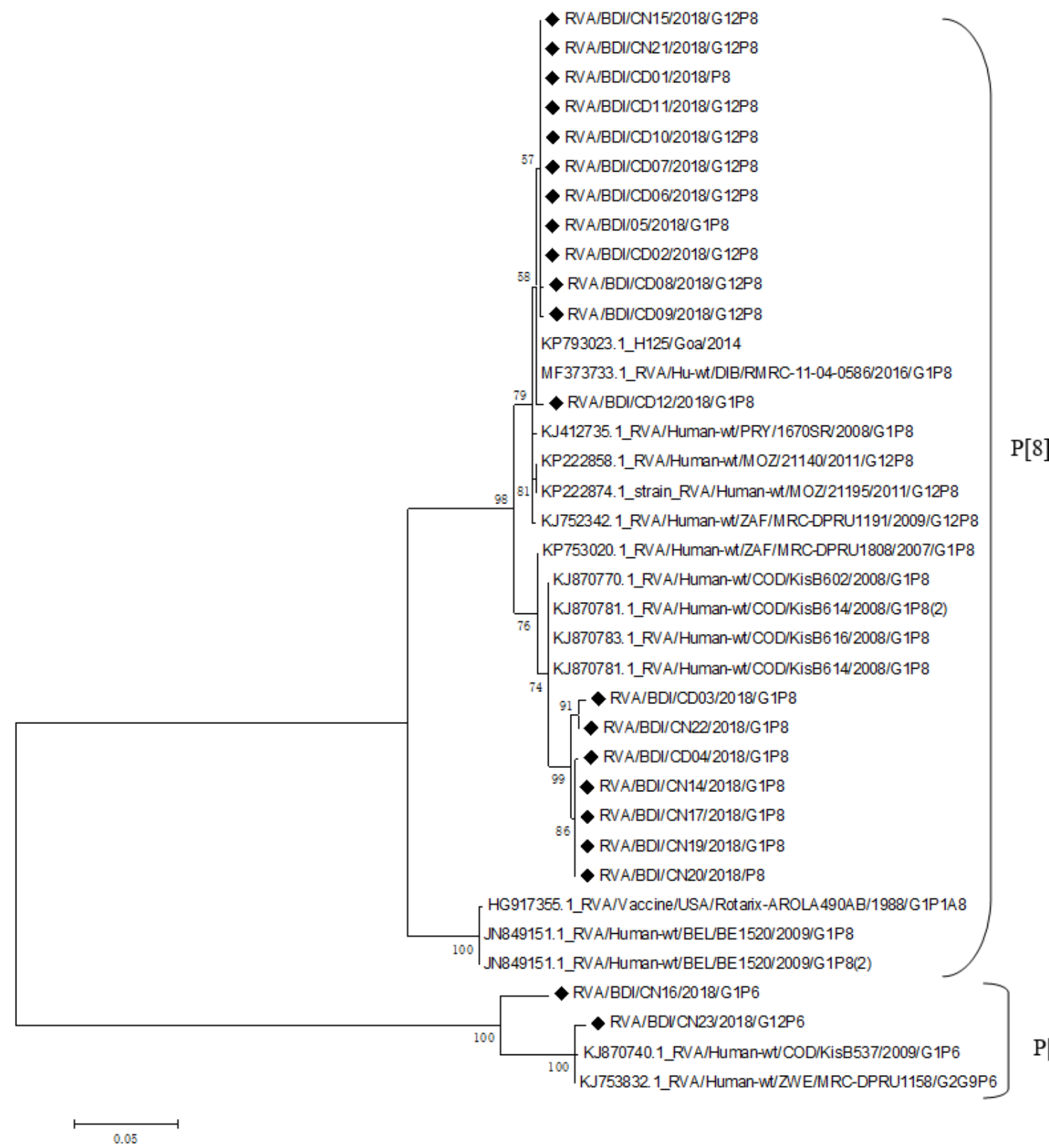

Figure 3. Phylogenetic tree of the partial VP4 gene nucleotide sequences of Group A rotavirus strains circulating in Mutaho health district and Bujumbura Municipality, Burundi. This diagram depicts the degree of similarity between VP4 nucleotide sequences of rotavirus strains from Burundi and known rotavirus reference strains from GenBank database. Rotavirus reference strains are indicated by accession numbers while rotavirus strains from this study are indicated by a filled diamond symbol.

\section{Discussion}

The objective of this study was to determine the prevalence and molecular characteristics of Group A rotavirus strains causing acute diarrhea among children under five years of age in Mutaho health district and Bujumbura Municipality, Burundi.

This study established that the overall prevalence of rotavirus infections was $6.2 \%$. However, monthly detection rate varied significantly and showed a peak reaching $15.7 \%$ in July, the driest month of the year in Burundi (WBG, 2019; Climate-data.org, 2019). Rotavirus detection rate increased significantly as the level of precipitation went down. This seasonal pattern of rotavirus infections is characteristic of respiratory virus like influenza. It could be attributed to airborne spread of aerosolized rotavirus-laden particles that are ingested. In fact, it is believed that rotavirus is spread predominantly through fecal-oral transmission, through water, personto-person contact or contaminated environmental surfaces. However, a number of authors suggested that rotavirus may also spread through the air (Levy, Hubbard, \& Eisenberg, 2009). Dry conditions would tend to 
encourage the formation of virus-laden dust from fecally contaminated diapers, bedding and clothing. Also, small particles would tend to stay suspended in the air and then reach a susceptible individual (Brandt et al., 1982). A similar seasonal pattern of rotavirus infections was described in Kenya, Zambia and Bangladesh (Levy et al., 2009). Further, we noted that rotavirus was significantly more prevalent in Bujumbura Municipality than Mutaho health district. This could be attributed to difference in period and duration of sample collection in these two areas. In Bujumbura Municipality, sample collection started later when the dry season was imminent.

The findings from this study revealed that vaccinated children were not at a lesser risk for rotavirus infections, in comparison with non-vaccinated children. This could be attributed to the emergence and increasing importance of G12 rotavirus strains among other factors. These emerging strains have the potential to challenge the efficacy of rotavirus vaccines currently used i.e. Rotarix (GSK Biologicals, Rixensart, Belgium) and RotaTeq (Merck \& Co., Whitehouse Station, NJ, USA) as they share neither G nor P-type with these vaccines. The monovalent Rotarix vaccine comprises a G1P[8] human rotavirus strain while the pentavalent vaccine RotaTeq is a human-bovine reassortant vaccine comprising the genotypes G1, G2, G3, G4, G9 and P[8] on a bovine strain background (Cunliffe et al., 2009). The genotype G12, identified first in 1990 in the Philippines (Taniguchi et al., 1990), was found in Burundi as well, with considerable proportions (46.2\%, 12/26). In this study, it was predominantly in association with $\mathrm{P}[8]$ but also $\mathrm{P}[6]$ and $\mathrm{P}[4]$ at lesser frequencies. Since 1998, a decade after their first detection in the Philippines, G12 strains have been identified in Asia, Europe, South America, and North America, suggesting their possible emergence worldwide (Rahman et al., 2007). In Africa, G12 rotavirus strains were found in circulation in Ghana, Nigeria, Cote d'Ivoir and the Democratic Republic of Congo (Heylen et al., 2014; Ndze et al., 2013). They were also reported in East African countries including Kenya, Tanzania and Uganda (Ndze et al., 2013), suggesting the spread of these rotavirus strains across the globe due to increasing mobility of humans and animals.

The G12 rotavirus strains were found to be significantly predominant in Mutaho health district than in Bujumbura Municipality. Mutaho health district is a rural area where people depend mainly on agriculture and livestock including pig farming for their livelihood. These activities and less organized pig farming in particular might have contributed to the high prevalence of G12 genotype of Group A rotavirus in this area as pigs are believed to be a source of new rotavirus genotypes through a mechanism of genetic re-assortment. Human G12 rotavirus strains might result from evolution of porcine rotaviruses, especially through the exchange of genomic segments among the different host specific rotaviruses (Malik et al., 2014). This is consistent with findings from a study conducted in India which suggested that this emerging genotype might have a porcine origin in view of the degree of relatedness between human and porcine G12 rotavirus. Porcine rotavirus A strains with G12 genotype for which comparative sequence analysis clustered with human G12 strains with maximum identities of $93.6 \%$ to $94.5 \%$ at deduced amino acid level were first reported in India in 2006 (Malik et al., 2014).

The $\mathrm{G}$ and $\mathrm{P}$ genotypes identified in our study sites were previously reported in the Democratic Republic of Congo, Tanzania, Kenya and South Africa (Heylen et al., 2014; Moyo et al., 2014; Ndung'u et al., 2017; Magagula et al., 2015). In addition, the G/P genotype combination G1P[8] predominant in Bujumbura Municipality is recognized to be predominant worldwide and is responsible for $50-60 \%$ of rotavirus group A gastroenteritis among children globally (Moyo et al., 2014; Halloran et al., 2000). This also suggested that rotavirus strains spread across different countries of the globe as a result of human mobility.

The burden of rotavirus gastroenteritis among under 5 years children in post vaccine era highlighted by this study was also reported in many countries including Tanzania in 2007 where the prevalence of rotavirus infections was 18.1\% (Moyo et al., 2007), the Democratic republic of Congo (Heylen et al., 2014) and Kenya (Agutu et al., 2017). However, the overall prevalence of rotavirus infections observed in this study is lower than that reported in other studies conducted in other East African countries which reported a prevalence of $31.5 \%$ in Kenya, 26.4\% in Tanzania and 45.4\% in Uganda (Agutu et al., 2017; McHaile et al., 2017; Nakawesi et al., 2010). This could be attributed to differences in duration and period of study.

\section{Conclusion and recommendations}

The findings from this study documented rotavirus genotypes prevailing in Mutaho health district and Bujumbura Municipality and the emergence of G12 human rotavirus strains in these two areas but more significantly in Mutaho health district. Emerging G12 rotaviruses raise public health concerns as they share neither $\mathrm{G}$ nor $\mathrm{P}$ genotypes with currently used rotavirus vaccines and hence have the potential to challenge their efficacy. Therefore, we recommend to initiate and maintain a continuous rotavirus strain surveillance in Burundi so as to monitor trends in the occurrence of these prevailing and potentially emerging new strains. Data from such a surveillance would be helpful in the monitoring of rotavirus vaccines efficacy and also in the development and /or adaptation of rotavirus vaccination strategies. Furthermore, farmers should be given relevant information regarding organization and management of their farms so as to reduce the exposure of their livestock, especially pigs, to gastrointestinal diseases agents and cross-species transmission of rotavirus between humans and pigs. This study showed also seasonal variation in the prevalence of rotavirus infections. This could be important in 
vaccination strategies development.

\section{Nucleotide sequences accession numbers}

The nucleotide sequences for VP4 and VP7 genes of our study Rotavirus strains were submitted directly to GenBank and were assigned accession numbers from MK 685872 to MK 685896 for VP4 gene nucleotide sequences and from MK 685890 to MK 685896 for VP7 gene nucleotide sequences.

\section{Competing interests}

The authors declare that they have no competing interests.

\section{Acknowledgement}

We would like to express our gratitude to the administration of Mutaho Health District, different Health Districts located in Bujumbura Municipality, Mutoyi Hospital, Mutaho District Hospital and different Health Centers involved in this study. We would also like to thank parents/guardians of all children who participated in this study. The laboratory staff and Pediatric ward nurses of Mutoyi Hospital, Mutaho district Hospital, Bugendana, Rwisabi, Mirango, Kamenge, Kinama, Buterere health centers and the Prince Regent Charles Hospital contributed tremendously in this study. We are immensely grateful to the administration of the National Institute for Public Health in Burundi (INSP). This study was authorized and funded by the Burundian Ministry of Public Health and the Fight against HIV/ AIDS.

\section{References}

Abugalia, M., Luis, C., Kirby, A., Dove, W., Nakagomi, O., Nakagomi, T., \& Al., E. (2011). Clinical Features and Molecular Epidemiology of Rotavirus and Norovirus Infections in Libyan Children. Journal of Medical Virology, 83, 1849-1856. https://doi.org/10.1002/jmv.22141

AFRSN (African Rotavirus Surveillance Network). (2017). Laboratory Manual. The 11th African Rotavirus Surveillance Workshop. Pretoria, South Africa: University of Limpopo-Medunsa Campus. MRC Diarrheal Pathogen Research Unit.

Agutu, M. T., Ongus, J., Kombich, J., Kamenwa, R., Nyangao, J., Kagira, J., ... Bitek, A. (2017). Prevalence and genetic diversity of rotavirus infection in children with acute gastroenteritis in a hospital setting, nairobi Kenya in post vaccination era: A cross-sectional study. Pan African Medical Journal, 26, 1-12. https://doi.org/10.11604/pamj.2017.26.38.10312

Bernstein, D. I. (2009). Rotavirus overview. Pediatric Infectious Disease Journal, 28(SUPPL. 3), $50-53$. https://doi.org/10.1097/INF.0b013e3181967bee

Brandt, C. D., Kim, H. W. H. A., Rodriguez, W. J., Arrobio, J., Jeffries, B. C., \& Parrott, R. H. (1982). Rotavirus Gastroenteritis and Weather. Jornal of Clinical Microbiology, 16(3), 478-482.

Climate-data.org. (2019). Climate Data in Burundi- Gitega. Retrieved February 6, 2019, from https://en.climatedata.org/afrique/burundi-73/

Cunliffe, N. A., Ngwira, B. M., Dove, W., Nakagomi, O., Nakagomi, T., Perez, A., ... Mwansambo, C. C. V. (2009). Serotype G12 rotaviruses, Lilongwe, Malawi. Emerging Infectious Diseases, 15(1), 87-90. https://doi.org/10.3201/eid1501.080427

Desselberger, U., Manktelow, E., Li, W., Cheung, W., Iturriza-Gomara, M., \& Jim, G. (2009). Rotaviruses and rotavirus vaccines. British Medical Bulletin, 90, 37-51. https://doi.org/10.1093/bmb/ldp009

Fischer, T. ., \& Gentsch, J. . (2004). Rotavirus typing methods and algorithms. Reviews in Medical Virology, 14(2), 71-82. Retrieved from http://ovidsp.ovid.com/ovidweb.cgi?T=JS\&PAGE=reference \&D=emed6\&NEWS=N\&AN=2004115475

GAVI. (2013). Burundi launches a new vaccine against rotavirus diarrhoea. Retrieved November 27, 2018, from http://www.gavi.org/library/audio-visual/videos/burundi-launches-a-new-vaccine-against-rotavirusdiarrhoea/: www.gavi.org/

Gouvea, V., Glass, R. I., Woods, P., Taniguchi, K., Clark, H. F., Forrester, B., \& Fang, Z. Y. (1990). Polymerase chain reaction amplification and typing of rotavirus nucleic acid from stool specimens. Journal of Clinical Microbiology, 28(2), 276-282.

Greenberg, H. B., \& Estes, M. K. (2009). Rotaviruses: From Pathogenesis to Vaccination. Gastroenterology, 136(6), 1939-1951. https://doi.org/10.1053/j.gastro.2009.02.076

Halloran, F. O., Lynch, M., Cryan, B., Shea, H. O., \& Fanning, S. (2000). Molecular Characterization of Rotavirus in Ireland: Detection of Novel Strains Circulating in the Population. Journal of Clinical Microbiology, 38(9), 3370-3374.

Heylen, E., Batoko, L. B., Zeller, M., Stevens, S., De Coster, S., Conceição-Neto, N., ... Matthijnssens, J. (2014). Rotavirus surveillance in Kisangani, the Democratic Republic of the Congo, reveals a high number of unusual genotypes and gene segments of animal origin in non-vaccinated symptomatic children. PLoS ONE, 
9(6). https://doi.org/10.1371/journal.pone.0100953

Ianiro, G., Delogu, R., Fiore, L., \& Ruggeri, F. M. (2015). Genomic characterization and molecular investigation of VP7 epitopes of uncommon G10P[8] group A rotavirus strains detected in Italy in 2009. Journal of General Virology, 96(7), 1801-1810. https://doi.org/10.1099/vir.0.000123

Kapoor, A., Li, L., Victoria, J., Oderinde, B., Mason, C., Pandey, P., ... Delwart, E. (2009). Multiple novel astrovirus species in human stool. Journal of General Virology, 90(12), 2965-2972. https://doi.org/10.1099/vir.0.014449-0

Levy, K., Hubbard, A. E., \& Eisenberg, J. N. S. (2009). Seasonality of rotavirus disease in the tropics: A systematic review and meta-analysis. International Journal of Epidemiology, 38(6), 1487-1496. https://doi.org/10.1093/ije/dyn260

Magagula N B, Esona M D, Nyaga MM, Stucker KM, Halpin R A, Stockwell T B, Seheri M L, et al. (2015). Whole Genome Analyses of G1P[8] Rotavirus Strains From Vaccinated and Non-Vaccinated South African Children Presenting With Diarrhea. J Med Virol, 87(1), 79-101. https://doi.org/10.1002/jmv.23971.

Malik, Y. S., Kumar, N., Sharma, K., Sircar, S., Dhama, K., \& Bora, D. P. et al. (2014). Rotavirus diarrhea in piglets : A review on epidemiology, genetic diversity and zoonotic risks. Indian Journal of Animal Sciences, 84(10), 1035-1042.

McHaile, D. N., Philemon, R. N., Kabika, S., Albogast, E., Morijo, K. J., Kifaro, E., \& Mmbaga, B. T. (2017). Prevalence and genotypes of Rotavirus among children under 5 years presenting with diarrhoea in Moshi, Tanzania: A hospital based cross sectional study. BMC Research Notes, 10(1), 4-9. https://doi.org/10.1186/s13104-017-2883-3

Moyo, S. J., Blomberg, B., Hanevik, K., Kommedal, O., Vainio, K., Langeland, N., \& Maselle, S. Y. (2014). Genetic Diversity of Circulating Rotavirus Strains in Tanzania Prior to the Introduction of Vaccination. PLoS ONE, 9(5), e97562. https://doi.org/10.1371/journal.pone.0097562

Moyo, S. J., Gro, N., Kirsti, V., Matee, M. I., Kitundu, J., Maselle, S. Y., ... Myrmel, H. (2007). Prevalence of enteropathogenic viruses and molecular characterization of group A rotavirus among children with diarrhea in Dar es Salaam Tanzania. BMC Public Health, 7(1), 1-6. https://doi.org/10.1186/1471-2458-7-359

Nakawesi, J. S., Wobudeya, E., Ndeezi, G., Mworozi, E. A., \& Tumwine, J. K. (2010). Prevalence and factors associated with rotavirus infection among children admitted with acute diarrhea in Uganda.

Ndung'u, J., Nyangao, J., Mbae, C., Sang, C., Njagi, E., Ngeranwa, J., ... Kariuki, S. (2017). Molecular characterization of group A rotaviruses in Mukuru slums Kenya : detection of novel strains circulating in children below 5 years of age. BMC Research Notes, 4-11. https://doi.org/10.1186/s13104-017-2611-z

Ndze, V. N., Papp, H., Achidi, E. A., Gonsu, K. H., Laszlo, B., Farkas, S., .. Odama, A. M. T. (2013). One Year Survey of Human Rotavirus Strains Suggests the Emergence of Genotype G12 in Cameroon. Journal of Medical Virology, 85, 1485-1490. https://doi.org/10.1002/jmv

PATH. (2013). Rotavirus disease and vaccines in Africa, 1-2. Retrieved from http://www.path.org/publications/files/VAD_rotavirus_ethiopia_fs.pdf

Rahman, M., Matthijnssens, J., Yang, X., Delbeke, T., Arijs, I., Taniguchi, K., ... Iftekharuddin, N. (2007). Evolutionary History and Global Spread of the Emerging G12. Journal of Virology, 81(5), 2382-2390. https://doi.org/10.1128/JVI.01622-06

Tamura, K., \& Nei, M. (1993). Estimation of the Number of Nucleotide Substitutions in the Control Region of Mitochondrial DNA in Humans and, 10(3).

Tamura, K., Stecher, G., Peterson, D., Filipski, A., \& Kumar, S. (2013). MEGA6: Molecular Evolutionary Genetics Analysis Version 6 . 0, 30(12), 2725-2729. https://doi.org/10.1093/molbev/mst197

Taniguchi, K., Urasawa, T., Kobayashi, N., Gorziglia, M., \& Urasawa, S. (1990). Nucleotide Sequence of VP4 and VP7 Genes of Human Rotaviruses with Subgroup I Specificity and Long RNA Pattern : Implication for New G Serotype Specificity. Journal of Virology, 64(11), 5640-5644.

WBG (The World Bank Group. (2019). Climate Data in Burundi. Retrieved February 6, 2019, from https:/climateknowledgeportal.worldbank.org/country/burundi/climate-data-historical

WHO (World Health Organization). (2009). Manual of rotavirus detection and characterization methods Manual of rotavirus detection and characterization methods Immunization, Vaccines and Biologicals. World Health Organization, Department of Immunization, Vaccines and Biologicals. Retrieved from www.who.int/vaccines-documents/

WHO, U. (2013). Diarrhoea: Why children are still dying and what can be done. Geneva (Vol. 84). Retrieved from http://ir.obihiro.ac.jp/dspace/handle/10322/3933 